\title{
BIMBINGAN TEKNIS PENERAPAN CYBERCOUNSELING MENGATASI KECEMASAN REMAJA PADA TATANAN NEW NORMAL BAGI KONSELOR SEBAYA DI PUSAT INFORMASI KONSELING (PIK-R) BANJARMASIN
}

\author{
Sulistiyana dan Akhmad Sugianto
}

FKIP, Bimbingan dan Konseling, Universitas Lambung Mangkurat

E-mail : sulis.bk@ulm.ac.id, sugianto.bk@ulm.ac.id

\begin{abstract}
ABSTRAK
Minimnya pengetahuan dan keterampilan konselor sebaya dalam menggunakan cybercounseling menjadi salah satu faktor penghambat dalam pemberian proses layanan konseling sebaya. Kasus tersebut terjadi di organisasi PIK-R BKKBN Banjarmasin. Konselor sebaya mengalami kendala memberikan layanan pada konseli untuk konseling karena adanya aturan yang terkait pandemic covid-19. Berdasarkan permasalahan tersebut tim PKM memberikan solusi kepada konselor sebaya dengan memberikan Bimbingan Teknis Penerapan Cybercounseling Mengatasi Kecemasan Remaja Pada Tatanan New Normal Bagi Konselor Sebaya di Pusat Informasi Konseling Remaja (PIKR) Banjarmasin. Tujuan dilakukan kegiatan untuk memberikan keterampilan dan pemahaman kepada konselor sebaya tentang kompetensi, keterampilan, kode etik, proses dan tekhnik dalam pemberian cybercounseling untuk mengatasi kecemasan remaja. Secara teknis pelaksanaan berlangsung dalam 5 tahapan yaitu perencanaan, persiapan, pelaksanaan, evaluasi-Tindak Lanjut dan Pelaporan-Publikasi. Hasil yang didapatkan berdasarkan pelaksanaan PKM adalah konselor sebaya mendapatkan pemahamanan secara teoritis dan mendapatkan keterampilan secara praktis terkait penerapan cybercounseling.
\end{abstract}

Kata Kunci: Cybercounseling, Kecemasan, konselor Sebaya

\section{PENDAHULUAN}

Pandemi Covid-19 telah menyerang kurang lebih 200 negara di dunia. Belum ada satupun vaksin yang ditengarai mampu menahan laju infeksi pandemi ini. Hingga per 31 Mei 2020 Covid-19 menginfeksi 6,1 juta orang, yang sembuh 2.745 .000 dan 371.282 pasien meninggal dunia (Putri, 2020). Kejadian kasus pertama di Indonesia berasal dari Depok, Jawa Barat. Dua warga Depok mengidap Covid-19 setelah kontak fisik dengan warga
Jepang (Nuraini, 2020). Sebagai solusi atas permasalahan tersebut maka pemerintah melakukan kebijakan jaga jarak hingga Pembatasan Sosial Berskala Besar/PSBB dan mulai diterapkan 10 April 2020 berawal di DKI Jakarta (Wijaya, 2020) dan diikuti beberapa kota terdampak pandemi. dampak psikologis yang diterima oleh pasien atau keluarga pasien yang di diagnosis positif Covid-19. Mereka mengalami rasa cemas, tertekan, kekhawatiran secara berlebihan karena 
identitasnya atau privasinya bocor atau dibocorkan kepada publik sehingga berdampak sebagaian dikucilkan oleh lingkungan sekitarnya. Temuan kasus ini jika terus kejadiannya seperti begitu maka reaksi psikologis masyarakat yang melihat kenyataan tersebut kemungkinan akan menjadi tidak jujur saat merasakan gejala-gejala pandemik Covid-19 menyerang dirinya atau salah satu anggota keluarganya. Kasus dampak psikologis lainnya adalah sikap protektif yang berlebihan untuk menjaga orang lain yang disayanginya dari orang-orang yang didiagnosis positif Covid-19. Berupa reaksi psikologis dari penderita berupa sikap dan perilaku tidak jujur dengan riwayat penyakit yang dideritanya. Menutupi informasi tentang perjalanan dan persinggahan ke mana sebelumnya atau pernah kontak dengan penderita positif Covid-19 sebelumnya. Informasi yang diperlukan seperti ini kemungkinan tidak akan disampaikan kepada tenaga medis.

Berbagai studi telah membuktikan bahwa kehadiran pandemi Covid-19 telah mengganggu kesehatan mental manusia, salah satunya kecemasan (Cosic, Popovic, Sarlija, \& Kesedzic, 2020; Kar, Yasir Arafat, Kabir, Sharma, \& Saxena, 2020; Lee, 2020; Polizzi,
Lynn, \& Perry, 2020; Roy et al., 2020; Shanafelt, Ripp, \& Trockel, 2020; Vicario-Merino \& Munoz-Agustin, 2020; Zhang \& Ma, 2020). Untuk itu dibutuhkan metode penanganan kecemasan menghadapi Covid-19. salah satu metode yang dapat digunakan dalam membantu kesehatan mental manusia dalah konseling.

Pandemik covid- 19 tidak hanya mempunyai dampak terhadap psikologis manusia tetapi juga memulai adanya suatu pola perubahan dalam kehidupan, salah satu perubahan yang terjadi adalah proses bantuan pelayanan konseling melalui internet (Cybercounseling). Cybercounseling perlu dilakukan karena cybercounseling harus dipahami sebagai sebuah strategi bimbingan dan konseling (Bloom, 2004). Namun yang perlu diperhatikan adalah perangkat yang digunakan dalam cybercounseling itu sendiri. Tentu yang menjadi penentu utama adalah koneksi dengan internet sehingga dapat terjadi interaksi melalui website, email, facebook, video conference atau yahoo massengger maupun dalam bentuk yang lainnya. cybercounseling secara umum dapat didefinisikan sebagai praktek konseling profesional yang terjadi ketika konseli dan konselor berada 
secara terpisah dan memanfaatkan media elektronik untuk berkomunikasi melalui internet. Definisi ini mencakup web, email, chat, video conference, dan istilah lainnya yang relevan. Dalam kondisi seperti ini memungkinkan terjadinya komunikasi antara dua pihak bisa lebih cepat, lebih efisien dan lebih nyaman. Oleh karena itu, dapat dipahami bahwa cybercounseling merupakan proses berinteraksi dengan konselor secara online secara berkelanjutan melalui percakapan dari waktu ke waktu. Dalam istilah lain juga cybercounseling disebut sebagai interaksi secara tidak langsung berbasis teks dalam pertukaran komunikasi terapeutik antara konseli dan konselor dengan menggunakan surat eletronik. Disebut berbasis teks hanya untuk membedakannya dari layanan konseling berbasis suara yang ditandai dengan komunikasi timbal -balik antara konseli dan konselor secara langsung.

Konseling tersedia secara online baik secara proses dan untuk berbagai tujuan yang diarahkan pada tujuan bersama konseli, mulai dari meningkatkan kepercayaan sosial, membangun keterampilan, harga diri, dan memupuk rasa lebih kohesif, pengambilan keputusan atau kompetensi interpersonal. Dalam menghadapi masalah seperti yang dijelaskan itu, seringkali solusi pertama dalam mencari bantuan, dukungan maupun informasi dilakukan secara online. Remaja sekarang merasa sangat nyaman dengan email, handpone, atau pertemuan dengan teman-teman di chatting, videocall dibandingkan dengan pertemuan secara face to face. Dengan menggunakan internet memberi kemudahan kepada setiap orang untuk mendapatkan layanan, misalnya yang dibatasi dengan keadaan geografi dan fisik dapat dilakukan secara online. Sebagai konselor profesional perlu diperhatikan bahwa dalam hal kesehatan mental tidak semua konseli berpotensi mendapatkan layanan yang efektif secara online. Meskipun tidak semua orang suka menggunakan layanan online, tetapi banyak orang justru merasa ini sebagai sebuah kesempatan yang baik. Misalnya ada yang merasa malu dengan bertatap muka secara langsung lebih memilih layanan secara online. Tentu ini menawarkan tantangan sekaligus sebagai peluang.

Model konseling yang berlaku umum mengasumsikan bahwa konseling atau terapi hubungan menjadi hal yang penting bagi konseli dan konselor, 
memperhatikan situasi, tujuan konseling, dan beberapa faktor lainnya untuk menjaga privasi konseli. Selain itu membutuhkan seperangkat keterampilan dan komunikasi yang jelas serta kerangka kerja yang terstruktur namun fleksibel. Salah satu tantangan besar yang dihadapi konseling secara online adalah persepsi tentang keakuratan dari makna, nuansa, dan nada dalam konteks komunikasi berbasis teks. Sehubungan dengan itu, konsistensi dari seorang konselor atau terapis sangat dibutuhkan sehingga dapat memunculkan rasa kepercayaan konseli kepada konselor dalam membantu masalah yang dihadapi. Seorang konselor dapat diberi sebagai cybercounseling jika ia menjadi sumber informasi berbasis situs atau web berbasis interaktif; menerima atau pertukaran e-mail dengan konseli, bahkan untuk menjadwalkan janji; memberikan layanan online, seperti pengujian, konseling, atau penilaian; melalui media elektronik.

Menyadari bahwa pentingnya pelayanan cyberkonseling karena konteks masyarakat kekinian, maka seyogianya konselor perlu memahami tentang cybercounseling secara komprehensif. Terkait dengan pentingnya pelayanan cybercounseling Sibel Dincyurek dan Gulen Uygarer (2012) dalam hasil penelitiannya di Turky tentang pentingnya pelayanan bimbingan dan konseling di Turky, pandangan akademisi bahwa layanan konseling online akan berguna bagi siswa pemalu yang tidak bisa datang ke layanan konseling sekolah. Selain itu bahwa layanan konseling online dapat menyediakan waktu 24 jam dalam sehari. Dengan begitu akan memberi kesempatan untuk menjangkau siswa lebih luas. Dan konselor dapat memberikan layanan langsung kepada siswa secara bersama-sama. Untuk memberi pemahaman dasar konseptual pentingnya pelayanan cybercounseling maka pada bagian-bagian berikut ini akan diperlihatkan hasil kajian dan pembahasan secara konseptual tentang urgensi pelaksanaan layanan cybercounseling.

Berdasarkan hasil studi pendahuluan dengan meteode wawancara pada tangggal 29 juni 2020 via telepon bersama Pembina PIK Remaja kota Banjarmasin yang dinaungi oelh BKKBN Provinsi Kalimantan Selatan mengatakan bahwa terjadinya perubahan pola pelayanan pemberian konseling yang dulunya secara face to 
face sekarang berbasis internet dikarenakan adanya upaya pemerintah yang memberlakukan PSBB, Social distancing dan Physical distancing dalam hal ini kita sebagai warga masyarakat mempunyai tanggung jawab dalam mendukung upaya pemerintah oleh karena itu salah satunya adalah melakukan perubahan pola konseling melalui cybercounseling. Permasalahan Yang terjadi di lapangan bahwa konselor sebaya masih banyak yang belum memahami tentang bagaimana kompetensi, keterampilan, teknik dan strategi yang diberikan dalam proses bantuan melalui cybercounseling, sehingga menjadi suatu faktor penghambat dalam pemberian layanan. sementara itu kebutuhan untuk mendapatkan layanan dari pihak konseli meningkat karena adanya gangguan kecemasan yang dialami oleh para remaja sebagai dampak dari wabah covid-19. Dampak tersebut harus segera ditangani agar permasalahan individu dapat diselesaikan dan individu dapat menjalani kehiudupan sesuai dengan kondisi yang ada.

Mengacu dari permasalahan diatas tim pengabdian masyarakat memberikan solusi terhadap mitra PkM yaitu Bimbingan Teknis Penerapan
Cybercounseling Mengatasi Kecemasan Remaja Pada Tatanan New Normal Bagi Konselor Sebaya di Pusat Informasi Konseling Remaja (PIK-R) Banjarmasin yang dinaungi oleh BKKBN provinsi Kalimantan Selatan.

\section{METODE PELAKSANAAN}

Sasaran dalam kegiatan bimbingan teknis ini adalah konselor sebaya yang tergabung dalam organisasi PIK-R BKKBN kota Banjarmasin yang berjumlah 10 orang.

Pelaksanaan kegiatan menggunakan metode kolaboratiof konsultatif dengan menekankan kepada keterampilan teknis yang praktis kepada konselor sebaya yang dilakukan melalui 5 (lima) langkah yakni sebagai berikut ini.

1. Perencanaan, dilakukan dalam 5 (lima) langkah yakni sebagai berikut:

1) Melakukan analisis permasalahan terkini dengan menggunakan kajian literartur.

2) Melakukan diskusi bersama tim PkM untuk menentukan mitra PkM dan kegiatan yang akan dilakukan.

3) Menentukan mitra PkM dan kegiatan yang akan dilaksanakan 
4) Melakukan koordinasi kepada mitra PkM dalam hal ini adalah Pusat Informasi Konseling Remaja (PIK Remaja) kota Banjarmasin.

5) Melakukan kesepakatan bersama antara tim PkM dengan Mitra PkM tentang pelaksanaan PkM.

2. Persiapan, dilakukan dalam 3 (tiga) langkah yakni sebagai berikut:

1) Mengatur jadwal pelaksanaan bimbingan teknis.

2) Mempersiapkan topik materi penerapan cybercounseling untuk konselor sebaya yang tergabung dalam PIK Remaja kota Banjarmasin.

3) Menyusun rencana pelaksanaan bimbingan teknis dengan menggunakan metode ceramah, praktik, sharing pengalaman, diskusi dan Tanya jawab. .

4) Mendokumentasikan rencana pelaksanaan layanan bimbingan klasikal yang akan diberikan.

3. Pelaksanaan, dilakukan melalui 4 (empat) metode yang meliputi:

1) Registrasi

Registrasi peserta bimbingan teknis dilakukan 1 (satu) jam sebelum kegiatan berlangsung. Registrasi dilaksanakan dengan tujuan untuk merekam kehadiran peserta PkM dan sebagai data dalam pelaporan pelaksanaan PkM.

2) Ceramah

Tahapan ceramah dimaksudkan menyampaikan materi kegiatan pengabdian kepada masyarakat. Pembagian materi ceramah didasarkan pada kesepakatan materi yang sudah dibagi. Materi yang akan disampaikan berkaitan dengan: (1) konsep dasar cybercounseling meliputi hakikat, tujuan, manfaat, proses, tekhnik, media dan pendekatan (2) Penggunaan Strategi art Counseling sebagai salah satu tekhnik cybercounseling; (3) Praktik cybercounseling dengan menggunakan art counseling.

3) Sharing Pengalaman

Sharing pengalaman adalah kegiatan berbagi pengalaman mengimplementasikan pelaksanaan konseling secara tatap muka langsung dan menggunakan strategi cybercounseling. Sharing Pengalaman ini ditujukkan kepada seluruh peserta yang mengikuti kegiatan PkM dengan 
tekhnik FGD.

4) Tanya Jawab

Dalam pelaksanaan tahap tanyajawab peserta bimbingan teknis diberi kesempatan untuk bertanya tentang materi bimbingan teknis. Tanya jawab dilaukan dengan tujuan memberikan kesempatan kepada peserta untuk bertanya langsung tentang materi yang disampaikan agar para peserta dapat memahami secara komprehensif tentang materi yang disampaikan sebelum menuju ke praktikum.

5) Praktikum

Dalam pelaksanaan tahap praktikum peserta bimbingan teknis dibagi menjadi beberapa kelompok yang terdiri 2 orang setiap kelompok. kelompok yang sudah terbentuk akan berdiskusi untuk memainkan peran sebagai konselor dan siswa yang terkait dengan praktik penerapan cybercounseling dengan Teknik systematic disenzititation. kelompok yang praktikum akan dinilai secara langsung oleh kelompok lainnya (rekan sejawat) dan instruktur langsung. Proses penilaian dilakukan dengan cara melakukan pengamatan secara langsung kepada kelompok yang praktikum. setelah selesai praktikum para observer kelompok lain akan diberikan kesempatan untuk menyampaikan saran, masukan dan pertanyaan kepada kelompok yang sudah melaksanakan praktikum sehingga dsana terjadi proses Tanya jawab. diharpkan output dari bimbingan teknis yang dilaksanakan adalah konselor sebaya mempunyai pengalan bagaimana menerapkan cybercounseling dengan menggunakan Teknik dalam mengentaskan masalah.

4. Evaluasi-Tindak Lanjut: dilakukan melalui 2 (dua) langkah yakni sebagai berikut.

1) Melakukan evaluasi proses bimbingan teknis.

2) Melakukan evaluasi hasil bimbingan teknis.

5. Pelaporan-Publikasi: mengandung dua kegiatan utama yakni sebagai berikut.
1) Pelaporan
pelaksanaan pemberian Bimbingan teknis bimbingan dan konseling 
penguatan pendidikan karakter dalam pelayanan bimbingan dan konseling bagi guru bimbingan dan konseling sekeloh menengah pertama se-kabupaten tabalong dalam format Laporan Pengabdian kepada Masyarakat kepada pihak FKIP ULM.

\section{HASIL DAN PEMBAHASAN}

Kegiatan pengabdian kepada masyarakat yang di kemas dalam bentuk bimbingan teknis penerapan cybercounseling dalam mengatasi kecemasan remaja dalam gtatanan new normal, dimulai dengan pendekatan kelembagaan. Pihak mitra menyambut baik kegiatan yang dilakukan bersama dengan konselor sebaya yang tergabung dalam PIK-R Kota Banjarmasin. Kegiatan ini dimaksudkan agar konselor sebaya yang tergabung dalam PIK-R dapat memahami dan mengimplementasikan pelaksanaan proses konseling melalui cybercounseling yang mendukung adanya protokol kesehatan selama wabah covid-19. Melalui penerapan cybercounseling dengan Teknik systematic desinzititation, konselor sebaya dapat mengetahui dan mengaplikasikan Teknik yang diberikan dalam proses layanan konseling. Melalui kegiatan ini juga bermanfaat untuk melakukan pengembangan diri sebagai konselor sebaya dengan menambah wawasan keilmuan dan keterampilan dalam memberikan layanan konseling (Syafril, 2020).

Sasaran pengabdian masyarakat yaitu konselor sebaya yang tergabung dalam organisasi PIK-R kota Banjarmasin yang dinaungi oleh BKKBN Provinsi Kalimantan Selatan. Peserta yang dikirim oleh BKKBN berjumlah 10 orang peserta yang giat mengikuti kegiatan pengabdian ini. Melalui kegiatan ini ditemukan bahwa peserta kegiatan PkM berpotensi untuk mengembangkan dirinya sebagai konselor sebaya terkait bidang keilmuan dan keterampilan dalam proses layanan konseling. Hal ini terlihat dengan antusiasnya peserta kegiatan yang ikut berpartisipasi dalam pelaksannan kegiatan tersebut.

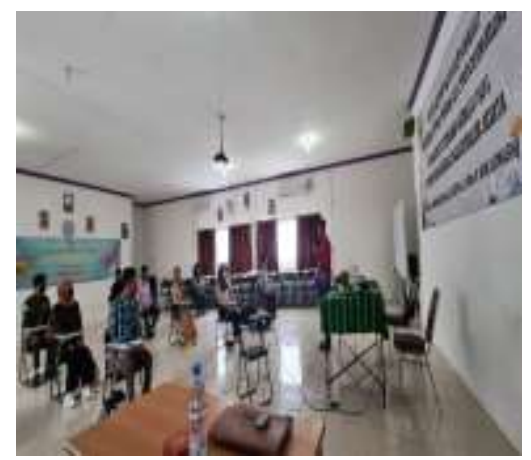

Gambar 1. Pemberian Materi Kepada Peserta 
Dari hasil kegiatan di lapangan menunjukkan bahwa konselor sebaya antusias dengan kegiatan pemaparan materi terkait penerapan cybercounseling dengan Teknik systematic disenzititation. Hal ini menunjukkan bahwa konselor sebaya sebagai seorang helper siap dalam melakukan pengembangan diri untuk menuju konselor sebaya professional. Indicator dari seorang konselor sebaya yang mau dalam mengembangkan dirinya dalah dengan mengikuti kegiatan yang dapat menambah wawasan keilmuan dan keterampilan sebagai seorang konselor sebaya. Dokumentasi pada gambar 2 adalah sesi tanya jawab. Pada saat ini, peserta bersemangat untuk bertanya maupun menjawab pertanyaan yang dilontarkan tim pelaksana.

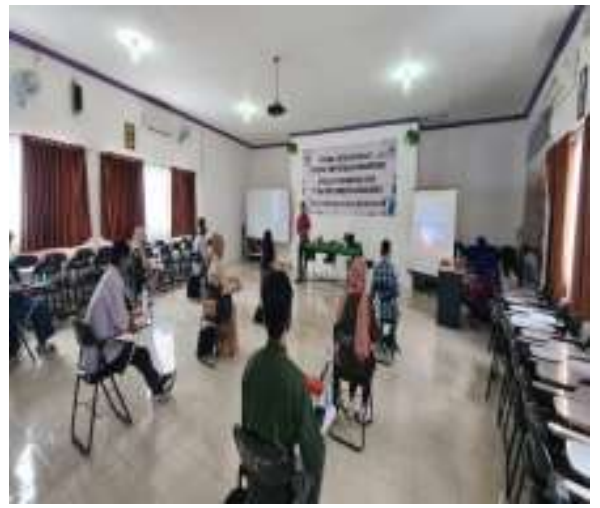

Gambar 2. Tanya Jawab

Bimbingan teknis penerapan cybercounseling dengan Teknik systematic disenzititation dikemas sebagai program latihan bagi anggota konselor sebaya PIK-R kota Banjarmasin dengan memberikan praktikum kepada peserta dengan harapan menjadi sebuah kegiatan yang menarik. Pemilihan teknik yang tepat dapat memberikan manfaat dalam proses bantuan layanan konseling (Sudjana, 1995; Widiani, Darmawan, \& Ma'mur, 2018; Simarmata, Mastuti, Tamimi, Melia, Yudha, \& Yuliansyah, 2019). Mengatasi kecemasan dengan penerapan cybercounseling menggunakan Teknik systematic disenzititation merupakan sebuah strategi layanan konseling yang dapat digunakan dalam layanan bantuan konseling untuk mengatasi masalah kecemasan (Ririanti Rachmayanie, 2020).

Sebagai suatu strategi, cybercounseling dengan Teknik systematic disenzititation memiliki proses yang harus dilalui dalam implementasinya sehingga akan terjadi penajaman keterampilan dalam konseling (Handayani, 2006; Rikarno, 2015). Dengan adanya strategi ini mereka sangat termotivasi untuk lebih meningkatkan kembali keilmuan terkait konseling dan keterampilan proses konseling. Gambar 3 menunjukan 
kegiatan peserta terlibat daslam proses pelaksanaan praktikum konseling. Peserta diminta untuk mengikuti paraktikum konseling yang dipandu oleh narasumber.

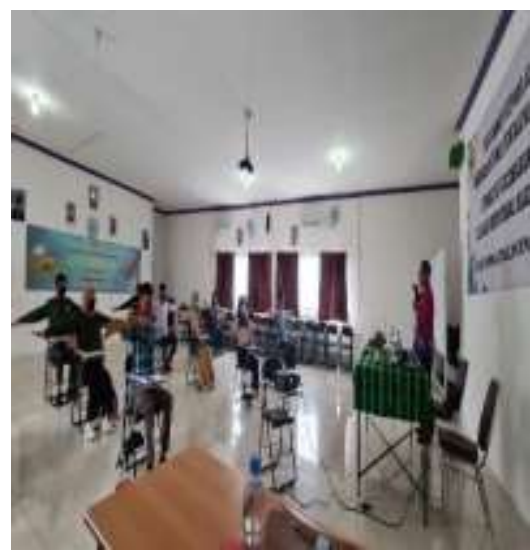

Gambar 3. Kegiatan Praktikum

Dalam pelaksanaan tahap praktikum peserta bimbingan teknis dibagi menjadi beberapa kelompok yang terdiri 2 orang setiap kelompok. kelompok yang sudah terbentuk akan berdiskusi untuk memainkan peran sebagai konselor dan siswa yang terkait dengan praktik cybercounseling dengan Teknik systematic disenzititation. proses penilaian dilakukan dengan cara melakukan pengamatan secara langsung kepada kelompok yang praktikum. setelah selesai praktikum para observer kelompok lain akan diberikan kesempatan untuk menyampaikan saran, masukan dan pertanyaan kepada kelompok yang sudah melaksanakan praktikum sehingga dsana terjadi proses
Tanya jawab. Output dari bimbingan teknis yang dilaksanakan adalah konselor sebaya sudah pandai dalam memberikan pelayanan konseling dengan menggunakan cybercounseling untuk mengtasi keceamasan remaja dalam menghadapi tatanan new normal.

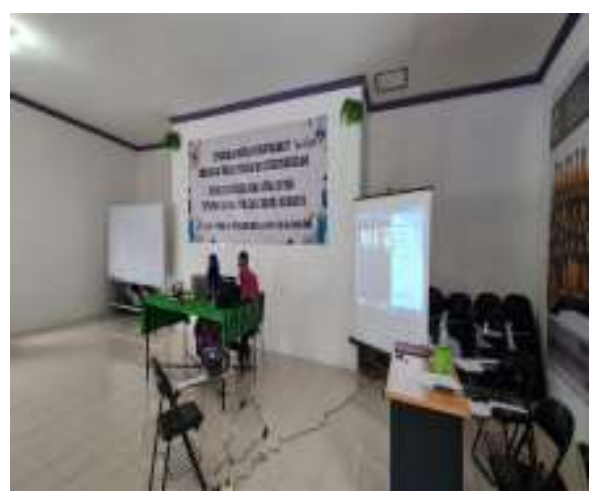

Gambar 4. Kegiatan Praktikum Cybercounseling

\section{KESIMPULAN}

Dalam kegiatan dapat disimpulkan bahwa pelayanan konseling dalam mengatasi kecemasan remaja oleh konselor sebaya PIK-R dapat dilakukan dengan tetap memperhatikan protocol kesehatan dan social distancing melalui penerapan cybercounseling dengan Teknik systematic disenzititation. Melalui kegiatan ini konselor sebaya dapat melakukan pengembangan diri dengan menambah wawasan keilmuan dan keterampilan dalam proses layanan konseling. 


\section{DAFTAR PUSTAKA}

Bloom, J.W., 7 Walz, G.R. (2004). Cybercounseling \& Cyberlearning. An Encore, US: CAPS Press.

Corey, G. (2013). Teori dan Praktek. Konseling dan Psikoterapi. Bandung: Refika Aditama.

Cosic, K., Popovic, S., Sarlija, M., \& Kesedzic, I. (2020). Impact of human disasters and Covid-19 pandemic on mental health: Potential of digital psychiatry. Psychiatria Danubina, 32 (1), 2531.

Finn, J., \& Barak, A. (2010). A descriptive study of e-counsellor attitudes, ethics, and practice. Counselling and Psychotherapy Research, 10(4), 268-277.

Hermawan, R. (2008). Membangun Sistem Agribisnis. Agroinfo. Yogyakarta.

Ifdil. (2011). Penyelenggaraan Layanan Konseling Online Sebagai Salah Satu Bentuk Pelayanan EKonseling dalam Syamsu Yusuf LN (2011) Contemporary and Creative Caunseling Techniques: How to Improve Your Counseling Skill and to be More Creative ini Counseling Sesion. Bandung: Rizqi Press

Illiyah, M. (2017). Konseling Anak dengan Terapi Menggambar dalam Membentuk Konsep Diri Positif Anak Di TPA Ash Shuffah Wonocolo Surabaya (Doctoral dissertation, UIN Sunan Ampel Surabaya).

Isman, A. (2003). Technology. The Turkish Online Journal of Educational Technology.2 (1).

Isnani, S. N. (2014). Bimbingan dan
Konseling Islam dengan Terapi Behavior dalam Memotivasi Belajar pada Anak Penderita Dyslexia Di Kelurahan Pagesangan Kecamatan Jambangan Surabaya (Doctoral dissertation, UIN Sunan Ampel Surabaya).

Kar, S. K., Yasir Arafat, S. M., Kabir, R., Sharma, P., \& Saxena, S. K. (2020). Coping with Mental Health Challenges During COVID-19. In S. . Saxena (Ed.), Coronavirus Disease 2019 (COVID-19), Medical Virology: from Pathogenesis to Disease Control (pp. 199-213). Singapore: Springer Nature Singapore Pte Ltd. https://doi.org/10.1007/978-98115-4814-7_16.

Koutsonika, Helen (2009) ECounseling: the new modality. Online Career Counseling achallenging opportunity for greek tertiary education. In: Proceedings of theWebSci'09: Society On-Line, 18-20 March 2009, Athens, Greece. (In Press)

Kraus, R., Stricker, G., \& Speyer, C. (2011). Online Counseling: A Handbook for Mental Health Professionals.San Diego: Academic Press.

Nuraini, R. (2020). Kasus Covid-19 Pertama, Masyarakat Jangan Panik. Retrieved March 2, 2020, from https://indonesia.go.id/narasi/ind onesia-dalamangka/ekonomi/kasus-covid-19pertama-masyarakat- janganpanik.

Polizzi, C., Lynn, S. J., \& Perry, A. (2020). Stress and coping in the time of COVID-19: Pathways to 
resilience and recovery. Clinical Neuropsychiatry, 17 (2), 59-62.

Prasetiawan, H. (2016). Cyber Counseling Assisted With Facebook To Reduce Online Game Addiction. Guidena: Jurnal Ilmu Pendidikan, Psikologi, Bimbingan dan Konseling, 6(1), 28-32.

Prasetyo, Y.R. \& Djuniadi. (2015). Implementasi E-konseling pada Social Learning Network. Edu komputika Juornal. 2 (2).http://journal.unnes.ac.id/sju/ indeks.php/edukom.

Prayitno. (2004a). Seri Layanan Konseling. L.5 (Layanan Konseling Perorangan). Padang: FIP. Jurusan BK.UNP.

Putri, G. S. (2020). Update Corona Dunia 31 Mei: 6,1 Juta Orang Terinfeksi, 2,7 Juta Sembuh. Retrieved from https://www.kompas.com/sains/r ead/2020/05/31/101403523/updat e-corona-dunia-31-mei-61-jutaorang-terinfeksi-27-juta-sembuh

Rachmayani, Ririanti \& Sulistiyana. (2020). Pelatihan Teknik Asertif Untuk Mengurangi Kecemasan Komunikasi Interpersonal Pada Siswa Kelas X Sma Negeri 12 Banjarmasin. Jurnal Al-Ikhlas, (

Rosana, E. (2016). Modernisasi Dalam Perspektif Perubahan Sosial. AlAdyan, 10 (1).

Roy, D., Tripathy, S., Kar, S. K., Sharma, N., Verma, S. K., \& Kaushal, V. (2020). Study of knowledge, attitude, anxiety \& perceived mental healthcare need in Indian population during COVID-19 pandemic. Asian Journal of Psychiatry, 51 (April), 1-7. Retrieved from https://doi.org/10.1016/j.ajp.202 0.102083

Sanyata, S. (2015). Perspektif Nilai dalam Konseling: Membangun Interaksi Efektif Antara Konselor- Klien. Paradigma, 1 (02).

Shanafelt, T., Ripp, J., \& Trockel, M. (2020). Understanding and Addressing Sources of Anxiety among Health Care Professionals during the COVID-19 Pandemic. JAMA - Journal of the American Medical Association, e1-e2.

Sibel Dincyurek, Gulen Uygarer. (2012). Conduct of Psychological Counseling and Guidance Services Over The Internet: Converging Communications. TOJET: The Turkish Online Journal of Educational Technology -July 2012. Volume 11 Issue 3. Diakses pada tanggal 28 April 2014 dari http://www.tojet.net/articles/v11i 3/1138.pdf.

Syafril, dkk. (2020). Peningkatan Kemampuan Manajemen Pemasaran Produk Unggulan Berbahan Dasar Naneas Kecamatan Mekarsari Barito Kuala Provinsi Kalimantan Selatan. Jurnal al-ikhlas. Vol 6 Nomor 1

Vicario-Merino, A., \& Munoz-Agustin, N. (2020). Analysis of the stress, anxiety and healthy habits in the Spanish Covid-19 confinement. Health Science Journal, 14 (2), 1-6.

Wijaya, C. (2020). PSBB Jakarta mulai 10 April selama dua minggu, namun pakar menyebut hasil efektif satu bulan untuk tekan Covid-19. Retrieved 
April 8, 2020, from https://www.bbc.com/indonesia/i ndonesia-52194441.

Zamani, Z. A., Nasir, R., \& Yusooff, F. (2010). Perceptions towards online counseling among counselors in Malaysia. Procedia Social and Behavioral Sciences $5,585-589$.
Zhang, Y., \& Ma, Z. F. (2020). Impact of the COVID-19 pandemic on mental health and quality of life among local residents in Liaoning Province, China: A cross-sectional study. International Journal of Environmental Research and Public Health, 17 (7), 1-12. 